\section{THE BEVERIDGE SECURITY PLAN}

CIR WILLIAM BEVERIDGE'S report on social $\checkmark$ insurance and allied services* has already been widely discussed, and it seems desirable to put on record its main features. The report includes, in discharge of its first duty, a comprehensive survey of social insurance and allied services as they exist to-day in Britain. This survey, showing just what provision is made, and how it is made, for different forms of need, is set out in Appendix $B$. The picture presented shows that provision for most of the many varieties of need through interruption of earnings and other causes that may arise in modern industrial communities has already been made in Britain on a scale not surpassed and scarcely rivalled in any other country. In respect of limitation of medical services Britain's achievement falls seriously short of what has been accomplished elsewhere, and its provision for cash benefit for maternity and funerals and its system for workmen's compensation are behind other countries. Secondly, social insurance and the allied services, as they exist to-day, are conducted by a complex of disconnected administrative organs, proceeding on different principles, doing invaluable service but at a cost in money and trouble for which there is no justification. In a system of social security better on the whole than can be found in almost any other country, there are serious deficiencies; by closer co-ordination, the existing social services could be made at once more beneficial and more intelligible to those whom they serve and more economical in their administration.

In proceeding from this comprehensive survey to the second duty, that of making recommendations, Sir William Beveridge lays down three guiding principles. First, any proposals for the future, while they should use to the full the experience gathered in the past, should not be restricted by consideration of sectional interests established in obtaining that experience. Secondly, organization of social insurance should be treated as one part only of a comprehensive policy of social progress. Thirdly, social security must be achieved by co-operation between the State and the individual. In offering security for service and contribution, the State should not stifle incentive, opportunity and responsibility; in establishing a national minimum, it should leave room and encouragement for voluntary action by each individual to provide more than that minimum for himself and his family.

The plan for social security set out in the report is based on these principles. It uses experience, but is not tied by experience. It is a limited contribution to a wider social policy in which not only want but also those other giants on the road to reconstruction-disease, ignorance, squalor and idleness-are attacked. It is first and foremost a plan of insurance, a scheme of social insurance against interruption and destruction of earning power, and for special expenditure arising at birth, marriage or death. The scheme is based on six fundamental principles : flat rate of subsistence benefit; flat rate of contribution; unification of administrative responsibility ; adequacy of benefit; comprehensiveness; and classification. Its aim is to make want unnecessary.

The proposals are set forth in detail because the principles underlying any practical reform ean only

- Social Insurance and Allied Services. Report by Sir William Beveridge. (Cmd. 6404.) Pp. 299. (London: H.M. Stationery Office, 1942.) 28. net. be judged by seeing how they would work in practice, and also because if a plan for social security is to come into operation when the War ends or soon after, there is no time to lose in getting the plan prepared as fully as possible. The plan covers all citizens without upper income limit, but has regard to their different ways of life. In relation to social security, the population falls into four main classes of working age and two others, below and above working age. These four classes consist of employees, or persons whose normal occupation is employment under contract of service ; others gainfully employed, including employers, traders and independent workers of all kinds; housewives, or married women of working age; and others of working age not gainfully employed. All these four classes will be insured for security appropriate to their circumstances, and all classes will be covered for comprehensive medical treatment and rehabilitation and for funeral expenses. Maternity grant, provision for widowhood and separation and qualification for retirement pensions will be secured to housewives by virtue of their husbands'contributions, while in addition to maternity grant, housewives who take paid work will receive maternity benefit for thirteen weeks to enable them to give up working before and after childbirth. All persons in the remaining three classes of working age will pay a single security contribution on a single insurance document each week or combination of weeks. In the first class the employer will also contribute, affixing the insurance stamp and deducting the employee's share from wages or salary. The contribution will differ from one class to another, according to the benefits provided, and will be higher for men than for women.

Subject to simple contribution conditions, all employees will receive benefit for unemployment and disability, pension on retirement, medical treatment and funeral expenses. Employers and other independent workers will receive all these, except unemployment benefit and disability benefit during the first thirteen weeks of disability. Those of working age not gainfully employed will receive all these except unemployment and disability benefit, but as a substitute for unemployment benefit, training benefit will be available for those in both these classes to assist them to find new livelihoods if their present ones fail. Unemployment benefit, disability benefit, basic retirement pension after a transition period, and training benefit will be at the same rate, irrespective of previous earnings, providing by itself the income necessary for subsistence in all normal cases. There will be a joint rate for a man and wife who are not gainfully occupied. Disability due to industrial accident or disease will be treated like all other disability for the first thirteen weeks; thereafter disability benefit at a flat rate will be replaced by an industrial pension related to the earnings of the individual, subject to a minimum and a maximum. After a period of unemployment, benefit will normally be subject to a condition of attendance at a work or training centre.

Pensions other than industrial will be paid only on retirement from work and may be claimed at any time after sixty-five for men and sixty for women, the rate of pension being increased above the basic rate if retirement is postponed. Medical treatment covering all requirements will be provided for all citizens by a national health service organized under the health departments, and post-medical rehabilita. tion treatment will be provided for all persons capable 
of profiting by it. A Ministry of Social Security will be established, responsible for social insurance, national assistance and encouragement and supervision of voluntary insurance, and will take over, so far as necessary for these purposes, the present work of other Government Departments and of local authorities in these fields.

All the principal cash payments will continue so long as the need lasts, without means test, and will be paid from a Social Insurance Fund, built up by contributions from the insured persons, from employers, and from the State. This is in accordance with the view that benefit in return for contributions, rather than free allowances from the State, is what the people of Britain desire, and that the money required should come from a fund to which tho recipients have contributed and to which they may be required to make larger contributions if the fund proves inadequate. The scheme thus preserves the contributory principle, but it also involves a pooling of risks except so far as separation of risks serves a social purpose ; there is no longer an admitted claim of the individual citizen to share in national insurance and yet to stand outside it, keeping the advantage of his individual lower risk, whether of unemployment or of disease or accident.

In this plan, which is in some ways revolutionary but largely a natural development, and could be put in operation in the immediate aftermath of the War, there are two features which call for particular note. First, it involves superseding the present system of approved societies giving unequal benefits for compulsory contributions - a system which is inconsistent with the policy of a national minimum, has disadvantages for insured persons and involves unnecessary administrative costs-although there is suggested retention of the association of 'friendly societies' with national health insurance on a new basis. Secondly, it involves superseding the present scheme of workmen's compensation and inclusion of provision for industrial accident or disease within the unified social insurance scheme, subject to (a) a special method of meeting the cost of this provision and $(b)$ special pensions for prolonged disability and grants to dependants in cases of death due to such causes.

In the forty-five years of its existence, the present system of dealing with the results of industrial accident and disease has, the report concludes, contributed little or nothing to the most important purpose of all, restoration of the injured employee to the greatest possible degree of production and earning as soon as possible. Post-medical rehabilitation has only just begun to receive practical attention. Costs of administration are higher in relation to workmen's compensation than they need be or than they are in compulsory social insurance, while the system affords no complete security for the payment of compensation and fails to secure maintenance of necessary income.

On balance, the reasons for distinguishing between accident and industrial disease in any employment and other causes of injury outweigh the reasons in favour of complete uniformity. The report also maintains that there is a good social reason for taking a different line, in part at least, about the dangers of industrial accident and disease. Accordingly, one part of the funds required for benefits, pensions and grants in respect of industrial accident and disease will be obtained by a levy on employers in industries scheduled as having materially more than the normal risk of accident or industrial disease as a whole. The levy will not cover the whole of the excess cost above the normal but only a prescribed proportion, and will be based on wages paid and on the degree of risk, so that it can be raised or lowered as the risk in any such industry or in any particular place of employment is found to be above or below expectation.

Exactly what industries should be scheduled as hazardous is a matter for further detailed inquiry, but the report makes an additional important proposal in regard to the machinery of administration. It is suggested that, in each industry scheduled as hazardous, and liable to the special levy, there should be set up a statutory association of employers and employees to deal with the problem of industrial accident and disease. The functions of such an association might include the promotion of safety in the industry, by co-operation with the department or departments responsible for safety regulations, by research into the causes of accidents, by propaganda and instruction, and in other ways; the promotion of measures for rehabilitation and re-employment in that industry, in co-operation with the general national organs for that purpose covering all industries; advice on the making of all regulations affecting safety in the industry, the scheduling of industrial disease, and methods of assessment of earnings ; collecting from individual employers their quotas of the total levy required in the industry, in accordance with a scheme to be prepared by the association and approved by the Ministry of Social Security; and the establishment of schemes to supplement the benefits statutorily secured to all injured employees.

The statutory associations should combine the management and the labour in each industry, and the main purpose of the proposal is, within the framework of general social security, to utilize the knowledge, initiative and interest of those concerned in each industry, first, in making it as safe as possible, and, secondly, in mitigating so far as is humanly possible the consequences of those accidents and injuries that defy prevention.

In regard to the administration of the scheme by a new Ministry of Social Security, the report contemplates the establishment of a Social Insurance Statutory Committee, of an advice bureau for citizens in every local Security Office, and of a Division of Statistics and Intelligence, under firstrate leadership and with adequate reserves, to make use not only of its own material but also of the experiences of other countries. The Ministry should be able to make grants for research in all matters where further knowledge might reduce the burdens on the Social Insurance Fund. Provision is to be made to prevent hardship to persons employed in the administration of the present insurance schomes who are displaced as a result of the changes and for whom suitable alternative employment is not available; but while social security under the new system will involve no great increase, if any, in the number of officials, it is unlikely to make large numbers of those now employed redundant at any early date.

The scheme involves three particular assumptions which are discussed in detail in the last part of the report. The first of these is a general scheme of children's allowances. Social insurance should be part of a policy of a national minimum, and a national minimum for families of every size cannot be secured 
in practice by a wage system which must be based on the product of a man's labour and not on the size of his family. The view is taken that children's allowances are essential if benefit during unemployment is not to be allowed to equal or exceed earnings during work. They should be non-contributory, provided wholly out of taxation, and not to any extent out of insurance contributions. Accordingly the report recommends that children's allowances should be provided at the cost of the Exchequer in respect of all children other than the first child when the parent is earning, and of the first child in addition during the interruption of earning. The actual allowance should be graduated according to the age of the child and a cash allowance of $8 s$. a week on an average, administered by the Ministry of Social Security, is suggested.

The second assumption is comprehensive health and rehabilitation services for prevention and cure of disease and restoration of capacity for work, available to all members of the community. This is in accordance with the definition of the objects of medical service as outlined by the Medical Planning Commission of the British Medical Association in its draft interim report. While no detailed proposals are advanced in the Beveridge report, it suggests the need for a further immediate investigation, in which the finance and the organization of medical services can be considered together, in consultation with the professions concerned and with the public and voluntary organizations which have established hospitals and other institutions. From the point of view of social security, a health service providing full preventive and curative treatment of every kind to every citizen without exception, without remuneration limit and without an economic barrier at any point to delay recourse to it, is the ideal plan. Accordingly it is proposed that the social security contributions shall include a payment in virtue of which every citizen will be able to obtain whatever treatment his case requires, at home or in an institution, medical, dental, or subsidiary, without a treatment charge.

In regard to rehabilitation, the report advances three general propositions. Rehabilitation must be continued from the medical through the post-medical stage until the maximum of earning capacity is restored, and a service for this purpose should be available for all disabled persons who can profit by it irrespective of the cause of their disability. Cash allowances to persons receiving rehabilitation services should be the same as training benefit, including removal and lodging allowances where required, and thirdly, the contributions paid by insured persons should, as with medical treatment, qualify them for rehabilitation service with further payment. The organization of the rehabilitation service is already under examination by the Ministry of Labour and National Service.

The third assumption, on which the whole report is based, is the maintenance of employment and the prevention of mass unemployment. Payment of unconditional cash benefits as of right during unemployment is satisfactory provision only for short periods of unemployment; after that, complete idleness even on an income has a demoralizing effect. The report proposes therefore that, after a certain period, unemployment benefit should be conditional upon attendance at a work or training centre. Not only is this proposal impracticable if it has to be applied by the hundred thousand, but also the only satisfactory test of unemployment, an offer of work, breaks down in mass unemployment. The probable and possible effects of the Plan for Social Security in stabilizing the demand for labour are among its advantages, but they are subsidiary and do not touch the main problem of maintaining employment. For that, other measures are needed, and unless such measures are prepared and made effective, much that otherwise might be gained through the Plan for Social Security will be wasted.

The Plan for Social Security thus advanced cannot be judged without reference to the concluding section of the report, in which the abolition of want as a practicable post-war aim is discussed. The rise in the general standard of living in Britain during the last thirty or forty years dernonstrates, first, that growing general prosperity and rising wages diminished want but did not reduce it to insignificance, and, secondly, that it is wrong to assume that the present War must bring economic progress for Britain, or for the rest of the world, to an end. New measures are needed to spread prosperity, and the plan is designed to meet that need. Freedom from want, in Sir William Beveridge's view, can be regarded as a post-war aim capable of early attainment on four conditions : after the War the nations must set themselves to co-operate for production in peace, rather than to plot for mutual destruction by war, whether open or concealed; the re-adjustments of British economic policy and structure that will be required by changed conditions after the War should be made so that productive employment is maintained; a plan for social security, that is to say, for income maintenance, should be adopted free from unnecessary costs of administration and other waste of resources; and finally, decisions as to the nature of the plan should be taken during the War.

If a plan for freedom from want, so far as social security can give it, is to be ready when the War ends, it must be prepared during the War. The decisions required now are of principle and execution - the decision to introduce a unified comprehensive seheme of social insurance, the decision to entrust administration of the scheme to a Ministry of Social Security, and the decision to appoint some person or body to prepare the necessary legislation and bring the scheme into being, so that it is ready when the War ends. The plan is put forward as part of a general programme of social policy and as a contribution towards the achievement of the social security named in the fifth clause of the Atlantic Charter. The report makes the points that the purpose of victory is to live into a better world than the old world; that each individual citizen is more likely to concentrate upon his war effort if he feels that his Government will be ready in time with plans for that better world, and that if those plans are to be ready in time they must be made now. The proposals are a sign of the belief that the object of government in peace and in war is the happiness of the common man.

"Freedom from want," concludes the report, "cannot be forced on a democracy or given to a democracy. It must be won by them. Winning it needs courage and faith and a sense of national unity; courage to face facts and difficulties and overcome them; faith in our future and in the ideals of fair-play and freedom for which century after century our forefathers were prepared to die; a sense of national unity overriding the interests of any class or section." 